\title{
ИНСТИТУЦИОНАЛЬНАЯ УСТОЙЧИВОСТЬ ПОДРАЗДЕЛЕНИЙ КОММЕРЧЕСКИХ БАНКОВ В СОВРЕМЕННЫХ УСЛОВИЯХ
}

\begin{abstract}
АНнотАция. Сложившаяся ситуация в банковской сфере России (а именно санкции, отзыв лицензий главным регулятором, сокращение числа банков и т. д.) обуславливает необходимость рассмотреть вопрос о структурных изменениях в этой сфере, а также ее устойчивости. В связи с этим, основываясь и проанализировав статистику Банка России по показателям институциональной насыщенности банковскими услугами по федеральным округам, а также сведения о наличии внутренних структурных подразделений кредитных организаций в количественном соотношении, сделан вывод о перспективах деятельности внутренних структурных подразделений коммерческих банков в современных условиях. Так, сокращение числа банков и их подразделений не влияет на институциональную устойчивость, поскольку процесс направлен на ее укрепление. Отзыв лицензий осуществляется в основном у банков, не имеющих в своей структуре подразделений. Очевидна концентрация банковских учреждений в европейской части России и дороговизна крупных банковских структур, что однозначно определяет необходимость существования подразделений в целях обеспечения банковскими услугами отдаленных территорий страны.

кЛючЕВЫЕ словА. Банковская система; структура коммерческих банков; внутренние структурные подразделения; кризис банковской системы; структурная устойчивость банковской системы.
\end{abstract}

ИНФОРМАЦИЯ О СТАТЬЕ. Дата поступления 24 ноября 2015 г.; дата принятия к печати 16 марта 2016 г.; дата онлайн-размещения 31 мая 2016 г.

I. V. Sergeyeva

Surgut State University,

Surgut, Russian Federation

\section{INSTITUTIONAL SUSTAINABILITY OF COMMERCIAL BANK DEPARTMENTS IN THE CURRENT CONTEXT}

\begin{abstract}
The existing situation in Russia's banking sector (namely, sanctions, revocation of licenses by the master regulator, decrease of number of banks, etc.) makes it necessary to consider an issue of structural changes in this area, as well as its sustainability. In this context, when centering on and analyzing the statistics of the Bank of Russia in terms of indicators of institutional saturation with banking services by Federal Districts, as well as the information on existence of internal structural units of credit institutions in proportion to their quantitative ratio, a conclusion is made about activity prospects for internal departments of commercial banks in the current context. Thus, reducing the number of banks and their operating units does not affect the institutional sustainability, as the process is aimed at its strengthening. Revocation of licenses is mainly performed with the banks having no departments in their structure. Concentration of banking institutions in the European part of Russia and expensiveness of big banking structures is evident, that categorically determines the necessity of department existence in order to provide the country's remote areas of with banking services.

KEYWORDS. Banking system; structure of commercial banks; internal structural operating units; crisis of banking system; the structural sustainability of banking system. ARTICLE INFO. Received November 24, 2015; accepted March 16, 2016; available online May 31, 2016.
\end{abstract}

(C) И. В. Сергеева, 2016

\section{Baikal Research Journal}


Банковская революция» $[1 ; 2]$ начала XX в. изменила облик современных банков не только с функциональной с точки зрения, но и со стороны формирования их структуры. Существенными факторами в этом направлении послужили дерегулирование мирового банковского бизнеса, а уже в начале XXI в. - и мировая финансовая глобализация [1].

Совокупность позитивных, а также негативных тенденций (развитие наукоемких, электронных и информационных технологий, уровень и острота конкуренции, рост операционных и временных издержек) привела к возможности и необходимости выходить банкам на новые и все более удаленные рынки. Формой проявления таких тенденций стала способность банков осуществлять свою деятельность не только самостоятельно, но и через своих «агентов», именуемых внутренними структурными подразделениями. Перечисленные изменения банковских систем коснулись практически всех стран, участвующих в мировом хозяйстве, в том числе и банковской системы России.

В ретроспективе банковская система России претерпевала различные изменения в своей структуре. Первые предпосылки становления современного состояния структуры банковской системы относятся к началу $90-\mathrm{x}$ гг. XX в., когда в результате банковской реформы 1987 г. была произведена реорганизация кредитной системы страны, в результате которой узаконенная децентрализация начиная с 1988 г. дала толчок развитию коммерческой банковской деятельности [3].

Благодаря указанной реформе сегодня банковская система России представлена двумя уровнями: во главе первого уровня стоит главный банк страны - Банк России, а на втором располагаются представительства иностранных банков и кредитные организации, включая их обособленные и внутренние структурные подразделения (рис. 1).

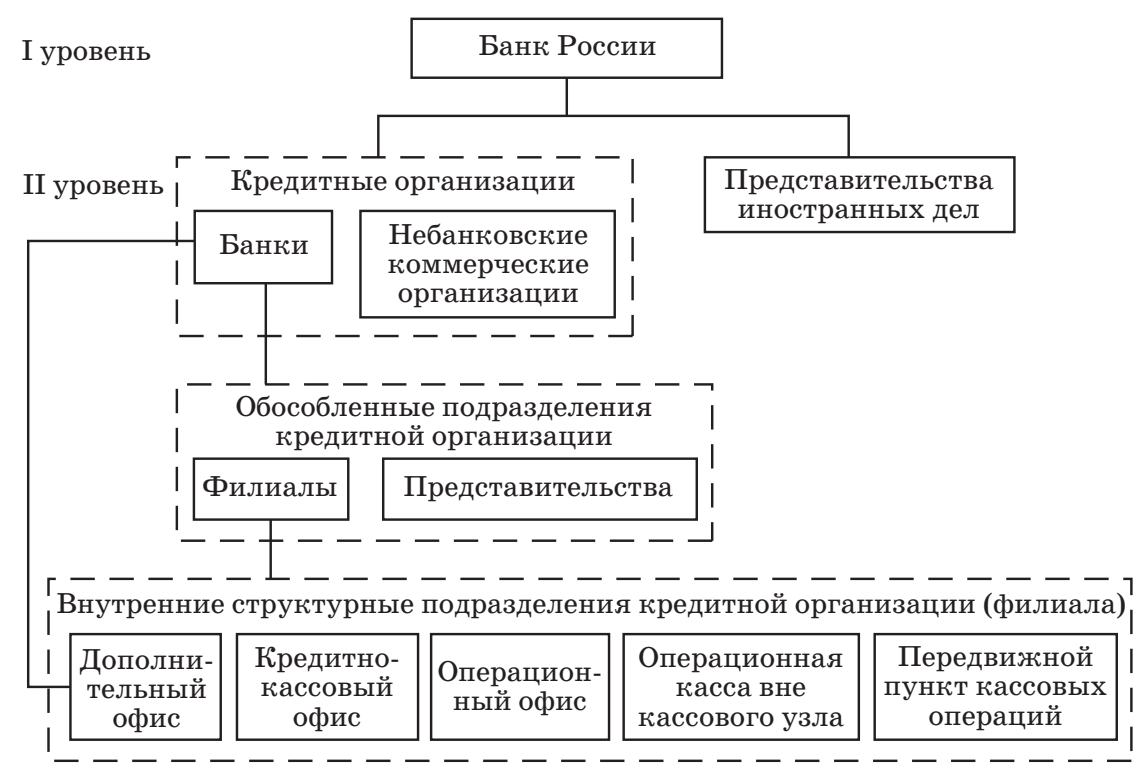

Рис. 1. Структурные элементы банковской систелы России

Глобальный финансовый и экономический кризис стал серьезным испытанием для российского финансового рынка [4, с. 69], в том числе и банковского сектора. Различные негативные факторы (ограничение доступности внешнего фондирования, отток частного капитала с российского рынка, ухудшение внешнеэкономи-

\section{Baikal Research Journal}


ческой конъюнктуры, снижение доверия к финансовой системе) привели к росту нестабильности на всех сегментах внутреннего финансового рынка. Банки страны реагировали на эти внешние неблагоприятные события по-разному, в зависимости от характера деятельности, реализации тех или иных рисков, банковской политики, а также неблагоприятных ожиданий в отношении банка у контрагентов [4, с. 69]. Указанные негативные тенденции сказались и на деятельности коммерческих банков и их внутренних структурных подразделений.

На современном этапе развития банковской системы страны можно констатировать изменение ее структуры. Особенно явно это выражается в количественном соотношении элементов банковской системы. Согласно официальной статистике Банка России четко прослеживается тенденция снижения количества кредитных организаций (в том числе банков) и филиалов, одновременно очевидна тенденция резкого роста их внутренних структурных подразделений (ВСП). Так, с 2001 по 2015 г. количество кредитных организаций и филиалов снизилось вдвое.

На фоне снижения количества кредитных организаций и филиалов очевидна тенденция резкого роста их ВСП: с 2006 г. по 2015 г. количество действующих кредитных организаций сократилось, и в то же время рост ВСП составил $33 \%$ !

Кроме того обращает на себя внимание тот факт, что произошли серьезные сдвиги в типах ВСП, открываемых кредитными организациями. За тот же промежуток времени наблюдается резкое увеличение дополнительных офисов почти в 2 раза, кредитно-кассовых офисов в Зраза, и самое масштабное увеличение операционных офисов в 18 раз. В 2010 г. в целом по России на 100 тыс. чел. приходилась 31 «точка» банковского обслуживания, тогда как в США этот показатель составлял 33,2, в Италии - 56,5, в Австрии - 61,8. В сравнении с количеством банков и их филиалов с показателями США в России количество банков меньше в 8 раз, а количество филиалов - почти в 25 раз. В Европе на 1000 жителей приходилось 46 банковских филиала, а в России только два [5].

Приведенная статистика свидетельствует об изменении структуры банковской системы страны и появлению новых направлений ее развития, к которым в периодической литературе относят укрупнение банковских учреждений; сокращение числа самостоятельных кредитных организаций, в том числе филиалов; рост внутренней сети действующих кредитных организаций [6].

Отметим, что ссылаясь на занимаемую долю банков с развитой сетью внутренних подразделений в структуре банковской системы страны, некоторые экономисты [7] однозначно утверждают, что в настоящее время внутренние структурные подразделения коммерческих банков наравне с филиалами могут выступать «системообразующими элементами банковской системы» .

Конец 2014-2015 гг. для российской банковской системы ознаменован новым этапом своего развития, обусловленным снижением экономического роста, повышением инфляции, заметном спаде инвестиционной активности, резком сокращении импорта, изменением потребительских настроений $[8$, с. 3]. Основной причиной подобных последствий стало ухудшение международных отношений, вылившихся в список санкций по отношению к России, в том числе и в банковской сфере.

«Современная российская банковская система представляет собой зрелый рыночный институт» $[9$, с. 9], который сформировался в результате ряда финансовых кризисов $(1998,2004,2008-2009,2014)$. Профессор И. Е. Никулина отмечает, что формирование банковской системы России носило «многоступенчатый характер ее становления», и, соответственно, процесс становления «происходил в условиях длительного спада и стагнации в экономике России, в связи с чем банковская система постоянно находилась в полустихийном процессе реструктуризации и выхода из кризисов» $[10$, с. 11$]$.

\section{Baikal Research Journal}


Кризис конца 2014 г. для банковской системы России не похож на предыдущие. Его природа лежит в международном политическом русле. От того, насколько быстро будет урегулирован внешнеполитический конфликт, зависят дальнейшие перспективы развития банковской системы России и ее элементов в целом.

В настоящее время нельзя не обратить внимание на изменения в структуре банковской системы в количественном соотношении, произошедшие с 2014 г. Несмотря на проводимую Банком России политику «зачистки» неблагонадежных банков, например за несоблюдение Федерального закона «О противодействии легализации (отмыванию) доходов, полученных преступным путем, и финансированию терроризма» от 7 августа 2001 г. № 115-Ф3 (далее - Закон № 115-ФЗ), численность кредитных организаций и их внутренних структурных подразделений можно считать относительно стабильной. Ведь «...удаление с рынка участников, осуществляющих сомнительные операции, не только не снижает устойчивость банковской системы, a, наоборот, ее повышает» $[11$, с. 60].

Согласно статистике Банка России об отзыве лицензий и ликвидации юридических лиц (табл. 1) очевидна тенденция к снижению количества банков. Отметим также, что значительно увеличилось количество кредитных организаций, у которых отозвана (аннулирована) лицензия на осуществление банковских операций, но не исключенных из Книги государственной регистрации. Если с 2005 по 2013 г. количество таких организаций составляло в среднем 139 единиц, то начиная с 2014 г. это количество резко возросло в среднем на 70 единиц.

На основании федерального банковского законодательства России отзыв лицензий осуществлялся по двум группам случаев:

- отзыв лицензии в соответствии с федеральными законами «О Центральном Банке Российской Федерации (Банке России)» от 10 июля 2002 г. № 86-ФЗ и «О банках и банковской деятельности» от 2 декабря 1990 г. № 395-1, а также приказа Банка России об отзыве лицензии, в результате которого кредитная организация не вправе совершать никакие банковские операции и сделки (нарушение законодательства в части оплаты уставного капитала и исполнения Закона № 115-ФЗ и т. д.) ${ }^{1}$;

- отзыв лицензии в связи с ликвидацией кредитных организаций без признаков банкротства (реорганизация в форме слияния / присоединения), по решению общего собрания учредителей кредитной организации (добровольное решение), в связи с прохождением процедуры банкротства (в соответствии с Федеральным законом «О несостоятельности (банкротстве) кредитных организаций» от 25 февраля 1999 г. № 40-ФЗ).

За 2014 г. количество кредитных организаций, у которых была отозвана лицензия на осуществление банковских операций по первой группе случаев, составило 8 организаций; в 2013 г. - 66; в 2012 г. - 112. По второй группе ситуация следующая: 2014 г. - 3; 2013 г. - 29; 2012 г. - 33. В динамике за период с 2001 г. очевидна тенденция динамичного снижения количества кредитных организаций.

Данный вывод о тенденции снижения числа коммерческих банков и их элементов подтверждается и в отчете Банка России «О развитии банковского сектора и банковского надзора в 2014 году»: «В 2014 году сохранилась тенденция последних лет к уменьшению количества действующих кредитных организаций» ${ }^{3}$ и их ВСП. Отмечается, что эти изменения коснулись не только крупных многофилиальных банков, но и столь значимых для экономики регионов - региональных и муниципальных банков [10; 12].

${ }^{1}$ Статистический бюллетень Банка России. 2015. № 4 (263). С. 288-289.

2 Количество внутренних структурных подразделений действующих кредитных организаций (филиалов) в территориальном разрезе по состоянию на 1.05.2010 [Электронный pecypc]. URL : http:// www.cbr.ru/statistics/print.aspx?file=bank_system/int_div_010510.htm\&pid=lic\&sid=itm_42701.

${ }^{3}$ Отчет о развитии банковского сектора и банковского надзора в 2014 году [Электронный ресурс]. URL : http://www.cbr.ru/publ/archive/root_get_blob.aspx\&doc_id=9878.

\section{Baikal Research Journal}

электронный научный журнал Байкальского государственного университета 
Диналика отзыва лицензий и ликвидации кредитных организаций

Таблица 1 в период 2001-2015 г2.

\begin{tabular}{|c|c|c|c|c|c|c|c|c|c|c|c|c|c|c|c|}
\hline $\begin{array}{c}\text { Показа- } \\
\text { тель }\end{array}$ & $\begin{array}{c}2001 \\
\text { (по } \\
\text { состо- } \\
\text { янию } \\
\text { на } \\
1 \text { янва- } \\
\text { ря) }\end{array}$ & 2002 & 2003 & 2004 & 2005 & 2006 & 2007 & 2008 & 2009 & 2010 & 2011 & 2012 & 2013 & 2014 & $\begin{array}{c}2015 \\
\text { (по } \\
\text { состо- } \\
\text { янию } \\
\text { на } \\
1 \text { апре- } \\
\text { ля) }\end{array}$ \\
\hline $\begin{array}{l}\text { Отзыв } \\
\text { (аннули- } \\
\text { рование) } \\
\text { лицензии }\end{array}$ & 664 & 876 & 1047 & 1201 & 1305 & 1366 & 1419 & 1495 & 1540 & 1555 & 1574 & 1594 & 1616 & 1638 & 1639 \\
\hline $\begin{array}{l}\text { Реорга- } \\
\text { низация } \\
\text { (в форме } \\
\text { слияния / } \\
\text { присоеди- } \\
\text { нения) }\end{array}$ & $\begin{array}{r}353 \\
(0 / 353)\end{array}$ & $\begin{array}{r}357 \\
(0 / 357)\end{array}$ & $\begin{array}{r}364 \\
(0 / 364)\end{array}$ & $\begin{array}{r}367 \\
(0 / 367)\end{array}$ & $\begin{array}{r}381 \\
(0 / 381)\end{array}$ & $\begin{array}{r}391 \\
(2 / 389)\end{array}$ & $\begin{array}{r}399 \\
(2 / 397)\end{array}$ & $\begin{array}{r}404 \\
(2 / 402)\end{array}$ & $\begin{array}{r}416 \\
(2 / 414)\end{array}$ & $\begin{array}{r}435 \\
(2 / 433)\end{array}$ & $\begin{array}{r}453 \\
(2 / 451)\end{array}$ & $\begin{array}{r}460 \\
(2 / 458)\end{array}$ & $\begin{array}{r}471 \\
(2 / 469)\end{array}$ & $\begin{array}{r}478 \\
(2 / 476)\end{array}$ & $\begin{array}{r}480 \\
(2 / 478)\end{array}$ \\
\hline $\begin{array}{l}\text { Преобра- } \\
\text { зованы в } \\
\text { филиалы } \\
\text { других } \\
\text { банков }\end{array}$ & 320 & 323 & 326 & 329 & 337 & 341 & 344 & 347 & 354 & 362 & 372 & 377 & 382 & 384 & 384 \\
\hline $\begin{array}{l}\text { Присое- } \\
\text { динены } \\
\text { к другим } \\
\text { банкам } \\
\text { (без обра- } \\
\text { зования } \\
\text { филиала) }\end{array}$ & 33 & 34 & 38 & 38 & 44 & 48 & 53 & 55 & 60 & 71 & 79 & 81 & 87 & 82 & 94 \\
\hline $\begin{array}{l}\text { Ликви- } \\
\text { дация в } \\
\text { связи с } \\
\text { добро- } \\
\text { вольным } \\
\text { решени- } \\
\text { ем участ- } \\
\text { ников }\end{array}$ & 4 & 4 & 0 & 0 & 0 & 0 & 0 & 0 & 0 & 0 & 0 & 0 & 0 & 0 & 0 \\
\hline $\begin{array}{l}\text { Ликви- } \\
\text { дация в } \\
\text { связи с } \\
\text { нару- } \\
\text { шением } \\
\text { законода- } \\
\text { тельства } \\
\text { в части } \\
\text { оплаты } \\
\text { уставного } \\
\text { капитала }\end{array}$ & 1 & 1 & 1 & 1 & 1 & 1 & 1 & 1 & 1 & 1 & 1 & 1 & 1 & 1 & 1 \\
\hline $\begin{array}{l}\text { Всего } \\
\text { лик- } \\
\text { види- } \\
\text { ровано } \\
\text { кре- } \\
\text { дитных } \\
\text { органи- } \\
\text { заций }\end{array}$ & 1022 & 1238 & 1416 & 1569 & 1687 & 1758 & 1819 & 1900 & 1957 & 1991 & 2028 & 2055 & 2088 & 2117 & 2120 \\
\hline
\end{tabular}

Источник: Информация о регистрации и лицензировании кредитных организаций [Электронный ресурс]. URL : http://www.cbr.ru/statistics/print.aspx?file=bank_system/inform_01.htm\&pid=pdkp_sub\&sid=inr_licko.

\section{Baikal Research Journal}


Согласно отчету Банка России официально признано, что крупные многофилиальные банки в 2014 г. продолжали оптимизацию своих региональных подразделений и снижали количество внутренних структурных подразделений. В результате количество внутренних структурных подразделений, приходящихся на 100 тыс. населения, уменьшилось с 30,3 на конец 2013 г. до 28,6 на конец 2014 г. М. С. Новоселова, Л. В. Мирошникова и О. Ю. Оношко связывают рост количества отзывов лицензий у коммерческих банков с кризисом ликвидности и со стремлением Банка России к укрупнению банковского сектора [13, с. 828-829].

Очевидно также сокращение количества действующих кредитных организаций на уровне регионов в 2014 г.: «число региональных банков уменьшилось с 425 до 375 по причине отзыва или аннулирования лицензий на осуществление банковских операций (38), присоединения к другим кредитным организациям (4), а также изменения места регистрации кредитных организаций (10). Одновременно получили лицензии на осуществление банковских операций две кредитные организации» ${ }^{2}$.

Таким образом, «статистические данные Банка России позволяют сделать вывод о чрезвычайной монополизации банковского сектора России, крайней неравномерности в обеспечении всеми видами банковских услуг субъектов Федерации» [12].

Деятельность любого коммерческого банка направлена на решение одной из важных задач: качественное и своевременное обеспечение банковскими услугами своих клиентов. В условиях сокращения численности банковских структур второго уровня системы показательной будет информация об обеспеченности населения банковскими услугами. Для этого рассмотрим статистику Банка России с точки зрения обеспеченности населения банковскими услугами кредитных организаций России по федеральным округам (табл. 2).

Таблица 2

Институциональная насыщенность банковскили услугали по кредитным организациял по состоянию на 1 января 2015 г.

\begin{tabular}{|l|r|r|r|}
\hline Федеральный округ & $\begin{array}{c}\text { Численность } \\
\text { населения, тыс. чел. }\end{array}$ & $\begin{array}{c}\text { Количество действующих } \\
\text { кредитных организаций }\end{array}$ & $\begin{array}{c}\text { Институциональная } \\
\text { насыщенность }\end{array}$ \\
\hline Центральный & 38945 & 504 & 0,013 \\
\hline Северо-Западный & 13847 & 64 & 0,005 \\
\hline Южный & 14006 & 43 & 0,003 \\
\hline Северо-Кавказский & 9659 & 28 & 0,003 \\
\hline Приволжский & 29718 & 92 & 0,003 \\
\hline Уральский & 12276 & 35 & 0,003 \\
\hline Сибирский & 19314 & 44 & 0,002 \\
\hline Дальневосточный & 6211 & 22 & 0,003 \\
\hline Крымский & 2294 & 2 & 0,0009 \\
\hline
\end{tabular}

Источник: Отчет о развитии банковского сектора и банковского надзора в 2014 году ГЭлектронный pecypc]. URL : http://www.cbr.ru/publ/archive/root_get_blob.aspx\&doc_id=9878.

В терминологии Банка России существует показатель для измерения обеспеченности услугами, который называется «индекс совокупной обеспеченности банковскими услугами» ${ }^{5}$ и рассчитывается как для кредитных организаций, так и для ВСП. Методика его расчета следующая: для каждого региона определяется отношение количества подразделений кредитных организаций к численности населения и делится на величину аналогичного показателя, рассчитанного для России в целом ${ }^{6}$.

\footnotetext{
${ }^{4}$ Отчет о развитии банковского сектора...

${ }_{5}^{5}$ Там же. С. 14.

${ }^{6}$ Там же. С. 103.
}

\section{Baikal Research Journal}

электронный научный журнал Байкальского государственного университета 
В рамках нашего исследования мы осуществляли расчет исходя из соотношения количества действующих кредитных организаций / ВСП и численности населения по федеральным округам. Как показали проведенные расчеты (см. табл. 2), безусловна преобладающая насыщенность банковскими услугами по численности населения Центрального федерального округа по отношению к остальным округам России.

Для сравнения приведем данные по институциональной насыщенности банковскими услугами по ВСП кредитных организаций (табл. 3).

Институциональная насыщенность банковскими услугами

Таблица 3

\section{по внутренним структурным подразделениям кредитных организаций по состоянию на 1 января 2015 2.}

\begin{tabular}{|l|r|r|r|}
\hline Федеральный округ & $\begin{array}{c}\text { Численность } \\
\text { населения, } \\
\text { тыс. чел. }\end{array}$ & $\begin{array}{c}\text { Количество действующих внутрен- } \\
\text { них структурных подразделений } \\
\text { кредитных организаций }\end{array}$ & $\begin{array}{c}\text { Институциональная } \\
\text { насыщенность }\end{array}$ \\
\hline Центральный & 38945 & 6911 & 0,177 \\
\hline Северо-Западный & 13847 & 2294 & 0,166 \\
\hline Южный & 14006 & 2559 & 0,183 \\
\hline Северо-Кавказский & 9659 & 779 & 0,081 \\
\hline Приволжский & 29718 & 4785 & 0,161 \\
\hline Уральский & 12276 & 2155 & 0,176 \\
\hline Сибирский & 19314 & 2694 & 0,139 \\
\hline Дальневосточный & 6211 & 1000 & 0,161 \\
\hline Крымский & 2294 & 124 & 0,054 \\
\hline
\end{tabular}

Источник: Отчет о развитии банковского сектора и банковского надзора в 2014 году [Электронный pecypc]. URL : http://www.cbr.ru/publ/archive/root_get_blob.aspx\&doc_id=9878.

Приведенные данные (см. табл. 3) показывают, что институциональная насыщенность ВСП кредитных организаций примерно одинакова (за исключением Северо-Кавказского и Крымского федеральных округов), что свидетельствует о структурной устойчивости российской банковской системы. ВСП коммерческого банка - главная составляющая деятельности современного банка. В инструкции Банка России «О порядке принятия Банком России решения о государственной регистрации кредитных организаций и выдаче лицензий на осуществление банковских операций» от 2 апреля 2010 г. № 135-И предусмотрено несколько типов ВСП: дополнительный офис, операционный офис, кредитно-кассовый офис, операционная касса вне кассового узла и иные формы. Отметим, что к категории «иных» ВСП относятся, например, передвижные пункты кассовых операций кредитных организаций (филиалов).

ВСП коммерческого банка - это важный элемент его структуры, который обладает рядом преимуществ, основными из которых являются низкие затраты на открытие и содержание (по отношению к филиалам и самим банкам), возможность размещения на территориях, отдаленных от головной структуры банка.

По данным Банка России, в 2015 г. зарегистрировано 37,5 тыс. ВСП (без учета передвижных пунктов кассовых операций). Мы рассчитали, какое количество банков обладают ВСП. Полученные данные разделили на восемь групп (рис. 2).

Согласно полученным данным из общего числа зарегистрированных кредитных организаций лишь $22 \%$ не имеют ВСП вообще - в основном, это банки, зарегистрированные в Москве и Московской области в форме обществ с ограниченной ответственностью, соответственно, остальные 78 \% ВСП обладают. Примечательно,

\section{Baikal Research Journal}


что 28 \% банков имеют в своей структуре до $50 \mathrm{BCП,} \mathrm{а} \mathrm{на} \mathrm{долю} \mathrm{банков} \mathrm{с} \mathrm{числен-}$ ностью свыше 1000 ВСП приходится около $1 \%$. К банкам с численностью свыше 1000 ВСП относятся так называемые банки с государственным участием, их всего четыре: Россельхозбанк, ВТБ24, РГС Банк, Сбербанк.

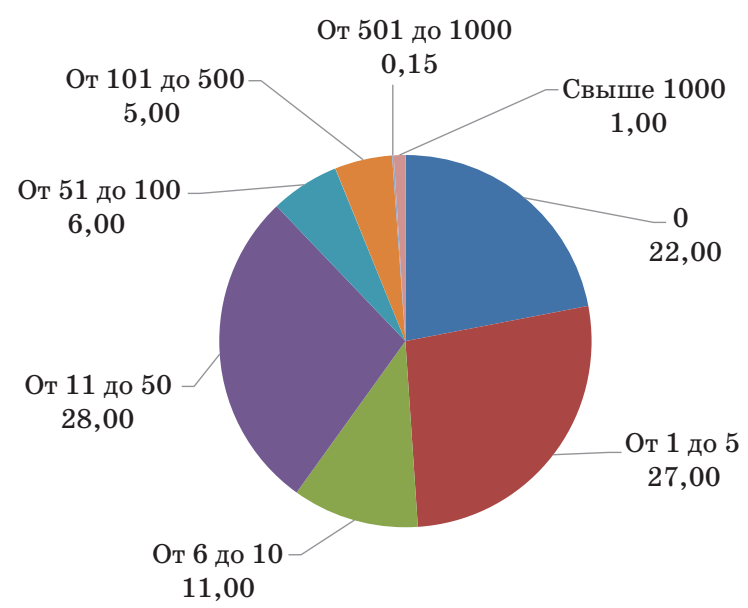

Рис. 2. Статистика наличия внутренних структурных подразделений у кредитных организаций по состоянию на 23 октября 2015 г., \% (Составлено по: URL : http://www.cbr.ru/credit/main.asp)

Таким образом, институциональная устойчивость ВСП коммерческих банков, на наш взгляд, обусловлена рядом факторов. Несмотря на сокращающуюся численность коммерческих банков, заинтересованность банков в ВСП остается. Сокращение численности банков и их ВСП происходит в виду нарушения федерального банковского законодательства, а зачистка банковской системы от неблагонадежных банков предполагает повышение устойчивости системы в целом. Кроме того, очевидна концентрация банковских структур в Центральном федеральном округе, что предполагает обеспечение населения банковскими услугами в отдаленных регионах страны на базе таких экономически целесообразных структур, как ВСП.

\section{Список использованной литературы}

1. Панова Г. С. Российские банки в зеркале мировых тенденций / Г. С. Панова // Банковские услуги. - 2002. - № 12. - С. 2-11.

2. Роуз П. С. Банковский менеджмент : пер. с англ. / Питер С. Роуз. - М. : Дело, 1995. $-768 \mathrm{c}$.

3. Рапопорт Л. А. Эволюция регулирования деятельности коммерческих банков в современной России / Л. А. Рапопорт // Финансы и кредит. - 2009. - № 39 (375). - С. 65-71.

4. Оношко О. Ю. Развитие банковской системы Российской Федерации / О. Ю. Оношко // Экономический кризис и возможные пути его преодоления : материалы междунар. науч.-практ. конф. г. Иркутск, 22-24 марта 2010 г. / под ред. В. И. Самарухи, Ж.-П. Гишара. - Иркутск : Изд-во БГУЭП, 2010. - С. 65-71.

5. Васильева А. И. Перспективы регионального развития банковской системы в связи с вступлением России в ВТО [Электронный ресурс] / А. И. Васильева. - Режим доступа : http://www.fa.ru/projects/mnsk/mnsk 4/4/Научное $\%$ 20направление $\%$ 20Кредитно-экономическое/ДКОиМП/Васильева.А.И.pdf.

6. Овчинникова О. П. Тенденции и закономерности развития банковской системы и филиальной сети в регионах России / О. П. Овчинникова, В. Ю. Чеснокова // Финансы и кредит. - 2008. - № 19 (307). - С. 2-9.

\section{Baikal Research Journal}


7. Потемкин С. А. Подходы к управлению экономической надежностью многофилиального банка / С. А. Потемкин, Н. Г. Новикова, Т. А. Ларина // Финансы и кредит. - 2010. № 35 (419). - C. 2-10.

8. Куликов М. В. Основные тенденции социально-экономического развития Российской Федерации на современном этапе / М. В. Куликов // Деньги и кредит. — 2015. — № 3. C. 3-7.

9. Дубинин С. К. Российская банковская система - испытание финансовым кризисом / С. К. Дубинин // Деньги и кредит. - 2015. - № 1. - С. 9-12.

10. Никулина И. Е. Программно-целевое управление банковской системой на региональном уровне / И. Е. Никулина. - Томск : Дельтаплан, 2003. - 280 с.

11. Петрова Т. И. Эффективность институциональной структуры банковской системы Российской Федерации / Т. И. Петрова // Деньги и кредит. - 2014. - № 1. - С. 57-62.

12. Счастная Т. В. Состояние региональной банковской системы в Российской Федерации / Т. В. Счастная, Д. Н. Чугуров // Проблемы учета и финансов. — 2014. — № 4 (16). C. 59-64.

13. Новоселова М. С. Стратегия сокращения деятельности коммерческих банков в современных условиях / М. С. Новоселова, Л. В. Мирошникова, О. Ю. Оношко // Известия Иркутской государственной экономической академии. - 2015. — Т. 25, № 5. - С. 827-833. DOI : 10.17150/1993-3541.2015.25(5).827-833.

\section{References}

1. Panova G. S. Russian banks as reflected in the mirror of world trends. Bankovskie uslugi= Banking Services, 2002, no. 12, pp. 2-11. (In Russian).

2. Rose Piter S. Commercial Bank Management. Richard D. IRWIN, Inc., 1991. 677 p. (Russ. ed.: Rose Piter S. Bankovsky menedzhment. Moscow, Delo Publ., 1995. 768 p.).

3. Rapoport L. A. Evolution of regulation of commercial bank activities in modern Russia. Finansy $i$ kredit $=$ Finance and Credit, 2009, no. 39 (375), pp. 65-71. (In Russian).

4. Onoshko O. Yu. Development of banking system of the Russian Federation. In Samarukha V. I., GisharZh.-P. (eds). Ekonomicheskii krizis i vozmozhnye puti ego preodoleniya. Materialy Mezhdunarodnoi nauchno-prakticheskoi konferentsii, Irkutsk, Mart, 2010 g. [Economic Crisis and Possible Ways of Overcoming it. Materials of International Research Conference, Irkutsk, March, 2010]. Irkutsk, Baikal State University Economics and Law Publ., 2010, pp. 65-71. (In Russian).

5. Vasilyeva A. I. Perspektivy regional'nogo razvitiya bankovskoi sistemy $v$ svyazi s vstupleniem Rossii $v$ VTO [Prospects of regional banking system development in the context of Russia's entrance into WTO]. Available at: http://www.fa.ru/projects/mnsk/mnsk4/4/ Научное\% 20направление\% 20Кредитно-экономическое/ДКОиМП/Васильева.А.И.pdf. (In Russian).

6. Ovchinnikova O. P., Chesnokova V. Yu. Trends and regularity of developing banking system and branch network in Russia's regions. Den'gi $i$ kredit $=$ Money and Credit, 2008, no. 19 (307), pp. 2-9. (In Russian).

7. Potemkin S. A., Novikova N. G., Larina T. A. Approaches to managing economic reliability of multidivisional banks. Finansy $i$ kredit = Finance and Credit, 2010, no. 35 (419), pp. 2-10. (In Russian).

8. Kulikov M. V. Main trends of current social and economic development of the Russian Federation. Den'gi i kredit = Money and Credit, 2015, no. 3, pp. 3-7. (In Russian).

9. Dubinin S. K. Banking system in Russia - trial by financial crisis. Den'gi i kredit= Money and Credit, 2015, no. 1, pp. 9-12. (In Russian).

10. Nikulina I. E. Programmno-tselevoe upravlenie bankovskoi sistemoi na regional'nom urovne [Program-target management of banking system at the regional level]. Tomsk, Deltaplan Publ., 2003. 280 p.

11. Petrova T. I. Efficiency of institutional structure in the Russian Federation. Den'gi $i$ kredit $=$ Money and Credit, 2014, no. 1, pp. 57-62. (In Russian).

12. Schastnaya T. V., Chugurov D. N. The state of regional banking system in the Russian Federation. Problemy ucheta $i$ finansov $=$ Problems of Accounting and Finance, 2014, no. 4 (16), pp. 59-64. (In Russian).

\section{Baikal Research Journal}


13. Novoselova M. S., Miroshnikova L. V., Onoshko O. Yu. Strategy of reducing commercial bank activities in the current context. Izvestiya Irkutskoy gosudarstvennoy ekonomicheskoy akademii $=$ Bulletin of Irkutsk State Economics Academy, 2015, vol. 25, no. 5, pp. 827-833. DOI: 10.17150/1993-3541.2015.25(5).827-833. (In Russian).

\section{Информация об авторе}

Сергеева Ирина Владилировна - аспирант, кафедра налогов и налогообложения, Сургутский государственный университет, 628412, г. Сургут, ул. Ленина, 1, e-mail: sergeeva_ iv86@mail.ru.

\section{Author}

Irina V. Sergeyeva - PhD Student, Chair of Taxes and Taxation, Surgut State University, 1 Lenin St., 628412, Surgut, Russian Federation; e-mail: sergeeva_iv86@mail.ru.

\section{Библиографическое описание статьи}

Сергеева И. В. Институциональная устойчивость подразделений коммерческих банков в современных условиях / И. В. Сергеева // Baikal Research Journal. — 2016. — Т. 7, № 3. — DOI : $10.17150 / 2411-6262.2016 .7(3) .10$.

\section{Reference to article}

Sergeyeva I. V. Institutional sustainability of commercial bank departments in the current context. Baikal Research Journal, 2016, vol. 7, no. 3. DOI: 10.17150/2411-6262.2016.7(3).10. (In Russian).

\section{Baikal Research Journal}

